\title{
CHRISTOPHE PELLET, Le théâtre de Marguerite Duras
}

\section{Elisa Borghino}

\section{(2) OpenEdition \\ Journals}

\section{Edizione digitale}

URL: https://journals.openedition.org/studifrancesi/23142

DOI: $10.4000 /$ studifrancesi.23142

ISSN: 2421-5856

\section{Editore}

Rosenberg \& Sellier

\section{Edizione cartacea}

Data di pubblicazione: 1 avril 2020

Paginazione: 217

ISSN: 0039-2944

\section{Notizia bibliografica digitale}

Elisa Borghino, «CHRIStOPHE PELLET, Le théâtre de Marguerite Duras», Studi Francesi [Online], 190 (LXIV | I) | 2020, online dal 01 mai 2020, consultato il 03 août 2021. URL: http://journals.openedition.org/ studifrancesi/23142 ; DOI: https://doi.org/10.4000/studifrancesi.23142

\section{Questo documento è stato generato automaticamente il 3 août 2021}

\section{(c) (†)}

Studi Francesi è distribuita con Licenza Creative Commons Attribuzione - Non commerciale - Non opere derivate 4.0 Internazionale. 


\title{
CHRISTOPHE PELLET, Le théâtre de Marguerite Duras
}

\author{
Elisa Borghino
}

\section{NOTIZIA}

CHRISTOPHE PELLET, Le théâtre de Marguerite Duras, Paris, Ides et Calendes, 2018, 104 pp.

1 Christophe Pellet ci accompagna in un viaggio alla scoperta di una Duras ancora poco conosciuta, ma la cui essenza scenica emerge attraverso le pagine del saggio che le dedica. Un incontro fortunato, quello con la scrittura teatrale di Marguerite Duras, che apre a dinamiche nuove, arcaiche e rinnovate. Dopo il diploma alla FEMIS - l'École nationale supérieure des métiers de l'image et du son - nel 1991, l'autore ha pubblicato una quindicina di testi presso l'Arche Éditeur, poi messi in scena da Stanislas Nordey o Jacques Lassalle. Ha inoltre realizzato egli stesso una decina di film, tra cui il lungometraggio Aujourd'hui, rien, ispirato a Cesare Pavese e Jean-Luc Lagarce.

2 Pellet ci riporta al momento in cui nella vita della scrittrice, regista e sceneggiatrice il palcoscenico non aveva ancora ceduto il passo allo schermo. E molto prima di ottenere il Prix Goncourt nel 1984 con L'amant, quando l'autrice di Moderato cantabile e La douleur ha prestato la sua voce al teatro. Siamo in quei favolosi anni Sessanta in cui i suoi adattamenti teatrali hanno conosciuto il successo della critica e del pubblico.

3 Per Duras il teatro è spazio di sperimentazione a scapito della fiaba. Luogo privilegiato nel ridare vigore a un linguaggio che lo scrittore trova presto esaurito, la scrittura scenica libera la prosa dai vincoli narrativi e descrittivi per raggiungere una nuova forma che va al di là di ogni genere e al di là di ogni misura. È in quel terreno creativo che i testi teatrali si fanno racconti e danno vita a una musica particolare, banale e sofisticata al tempo stesso, classica come il Racine da cui trae ispirazione, ma anche iperbolica e accidentata.

4 Un unico e solo alito creativo, proteiforme, che muta nel tempo e la cui sostanza resta tuttavia invariata contraddistingue un percorso che va dal romanzo al racconto, dal 
testo teatrale alla sceneggiatura di un film, e poi ancora dalla sceneggiatura al romanzo... Un andirivieni continuo, quasi posto al servizio di un'unica esigenza costante, quella della verità e dell'accuratezza della parola. Personaggi che a loro volta mutano senza sosta e che sembrano riprodurre all'infinito il dramma famigliare dove la figura della madre lotta incessantemente in un gioco di dolore con l'Indocina come sfondo abituale di ogni vicenda. E la parola si rinnova nel mutamento, come un'araba fenice pronta a morire e rinascere dalle proprie ceneri. 